\title{
Kemik-eklem hastalıklarının obezite ile ilişkisi
}

Betül KOÇAK ${ }^{\mathrm{a}}$, Aysun YÜKSEL ${ }^{\mathrm{b}}$

\section{ÖZET}

Obezite; kas ve iskelet sistemi üzerinde osteoartrit, osteoporoz ve sistemik enflamatuar romatizmal hastalıkları da içeren geniş bir hastalık yelpazesini etkilemektedir. Konu üzerine yapılan çalışmalar, genellikle beden kütle indeksi ile tayin edilen obezite varlığı ile diz osteoartrid prevalansı ve insidansı arasında ilişki olduğunu göstermiştir. Yürüyüş analizi, diz eklemi boyunca yükü azaltmak için kilo kaybının yararlı olduğunu göstermiştir, yaklaşık $0.5 \mathrm{~kg}$ ağırlık kaybı, adım başına iki ila dört kat yükte azalmaya neden olmaktadır. Öte yandan obezitenin kemik yapımını artırması ve çözülümünü azaltmasıyla toplam kemik metabolizmasının korunmasına yönelik etkisi, osteoporoz için göz ardı edilmemelidir. Beden kütle indeksinin 25 üzerinde olduğu, normal ağırlı̆ı̆ın üzerindeki hastalarda aktif olan hipertrofik adipositlerden adipositokin veya adipokin olarak tanımlanan mediatörler salınmakta, pro-enflamatuar aktiviteleri olan bu adipokinlerin enflamatuar romatizmal hastalıklar üzerine de etkisi bulunmaktadır. Kemik-eklem hastalıklarında obezitenin etkisi göz ardı edilmemeli ve klinik yaklaşımda tedavinin önemli bir parçası olarak yer almalıdır. Bu derlemede obezitenin kas-iskelet sistemi üzerinde oluşturduğu etkilerinin, güncel veriler ışığında incelenmesi amaçlanmıştır.

Anahtar Kelimeler: Osteoartrit, obezite, osteoporoz, romatizmal hastalıklar

\section{The relationship between bone-joint diseases and obesity}

\begin{abstract}
The effects of obesity on the musculoskeletal system includes a wide range of diseases such as osteoarthritis, osteoporosis and systemic inflammatory rheumatic diseases. Studies on the subject have shown that there is a relationship between the presence of obesity, which is usually determined by BMI, and the prevalence and incidence of knee osteoarthritis. Gait analysis showed that weight loss is beneficial for reducing load across the knee joint, it was found that about $0.5 \mathrm{~kg}$ of weight loss reduces the load by two to four times per step. On the other hand, the effect of obesity on the protection of total bone metabolism by increasing bone formation and decreasing its dissolution should not be ignored for osteoporosis. Mediators called adipocytokines or adipokines are released from activated hypertrophic adipocytes in obese or overweight patients, and these adipokines with pro-inflammatory activities also have an effect on inflammatory rheumatic diseases. The effect of obesity in bonejoint diseases should not be ignored and it should be an important part of the treatment in the clinical approach. In this review, it is aimed to evaluate the effects of obesity on the musculoskeletal system in the light of current data.
\end{abstract}

Keywords: Osteoarthritis, obesity, osteoporosis, rheumatic diseases

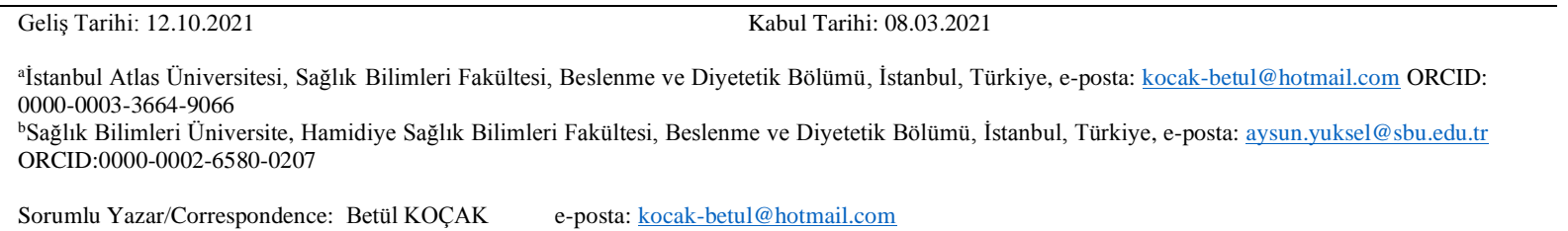

Atıf: Koçak B, Yüksel A. Kemik-eklem hastalıklarının obezite ile ilişkisi. Sağlık ve Yaşam Bilimleri Dergisi 2021;3(1):97-100.

Citation: Kocak B, Yuksel A. The relationship between bone-joint diseases and obesity. Journal of Health and Life Science 2021;3(1):97-100. 


\section{GIRIŞ}

Obezite, besinlerle alınan enerjinin vücudun harcadığı enerjiden daha fazla olması sonucu beden kütle indeksinin (BKİ) 30 üzerinde olması durumudur. ${ }^{1}$ Obezite kronik hastalık olarak sınıflandırılan, Dünya Sağlık Örgütü (DSÖ) tarafindan riski en yüksek 10 hastalıktan biri olarak kabul edilen bir sağlık sorunudur. $^{2}$ DSÖ tarafindan obezite, vücut yağ miktarında sağlığı olumsuz yönde etkileyecek kadar aşırı veya anormal artışın olması olarak tanımlanmıştır. ${ }^{3}$

Tüm dünyayla benzer şekilde ülkemizde de obezite prevalansı ve obeziteyle ilişkili kronik hastalıkların görülme sıklığı yükselmektedir. Yaklaşık 25000 kişinin katıldığ 1 Türkiye Obezite ve Hipertansiyon Taraması (TOHTA) araştırmasında obezite prevalansının kadınlarda \%36, erkeklerde daha düşük olarak \%21.5 ve genel toplumda ise \%25 olduğu bulunmuştur. ${ }^{4}$

Obezite; diabetes mellitus, yüksek tansiyon, lipid seviyelerinde dengesizlik, koroner arter, MetS, eklem hastalıkları, ve uyku apnesi gibi diğer rahatsızlıklara da yol açarak yaşam kalitesini olumsuz yönde etkilemekte ayrıca kanser kaynaklı mortalite ve kanser insidansının artışı da obezite ile paralel şekilde artış göstermektedir. ${ }^{5}$

Küresel obezite prevalansı 1980 'den bu yana iki kat artış göstermiştir. ${ }^{6}$ İngiltere'de 1993-2012 yılları arasında aşırı kilolu ve obez yetişkinlerin oranı erkeklerde \%57.6'dan \%66.6'ya ve kadınlarda $\% 48.6$ 'dan \%57.2'ye yükselmiştir. Obeziteye neden olan faktörler tartışmalıdır. Obezitenin artışıyla ilgili yayınlanan Öngörü Raporu, “son yıllarda, kilo alımına karşı insani savunmasızlığımızı ortaya çıkaran karmaşık toplumsal ve biyolojik faktörler ağı" sonucunu rapor etmiştir. DSÖ, “fazla kilolu” (BKI>> $\left.25 \mathrm{~kg} / \mathrm{m}^{2}\right)$ ve "obez" (BKI $\left.>30 \mathrm{~kg} / \mathrm{m}^{2}\right)$ dahil olmak üzere BKİ'ye dayalı olarak çeşitli ağırlık sınıflamaları tanımlamıştır ${ }^{7}$. Obezite ayrıca sınıf I (BKİ 30-34.9 $\mathrm{kg} / \mathrm{m}^{2}$ ), Sinıf II (35-39.9 kg/m²) ve sinif III ('morbid obez' $\geq 40 \mathrm{~kg} / \mathrm{m}^{2}$ ) olarak alt sınıfa ayrılmaktadır. Daha yeni bir kategori de "süper obez" $\operatorname{dir}\left(\mathrm{BKI}>50 \mathrm{~kg} / \mathrm{m}^{2}\right){ }^{6}$ Birleşik Krallık'ta ki erkeklerin \%47'sinin ve (21 ile 60 yaşları arasındaki) kadınların \%36'sının, 2025 yılına gelindiğinde, obez olacağı tahmin ediliyor. Tahminler 2050 y1lı için daha da kötüdür; \%60 yetişkin erkek, $\% 50$ yetişkin kadın ve $\% 25$ çocuğun (16 yaş altı) obez olacağ

Obezitenin kas ve iskelet sistemine etkileri, hastalıklara ve fonksiyonel yetersizlik gelişmesine sebep olmaktadır. Obezitenin kas-iskelet sistemine etkilerine bakıldığında osteoartrit, osteoporoz ve sistemik enflamatuar romatizmaları içeren oldukça geniş bir hastalık yelpazesini oluşturmaktadır. ${ }^{8}$ Obezite ve kemik metabolizması arasındaki etkileşim karmaşıktır. Yağ dokunun iskelet üzerindeki etkilerine hem mekanik hem de biyokimyasal faktörler aracilık eder. Obezite, daha yüksek kemik mineral yoğunluğu ile karakterize edilse de kemik mikro mimarisi üzerinde yapılan çalışmalar çelişkili sonuçlar da göstermektedir. Çalışmaların çoğu, obezitenin iskelet kuvveti üzerinde olumlu bir etkiye sahip olduğunu göstermektedir ancak bu olumlu etkiler bölgeye bağımlıdır ve aslında obez bireyler belirli tipte kırıklar için risk altında olabilir. Mekanik yüklenme ve daha yüksek yağsız kütle, daha iyi sonuçlar ile ilişkilendirilirken, özellikle abdominal obezite ile gözlenen sistemik inflamasyon, olumsuz etkiler gösterebilir. Ağırlı kaybı müdahaleleri zamanla kemik yapısında kayba da neden olabilmektedir. ${ }^{9} \mathrm{Bu}$ derlemede obezitenin kas-iskelet sistemi üzerinde oluşturduğu etkilerin, güncel bulgular 1şı̆̆ında incelenmesi amaçlanmıştır.

\section{Obezite ve Diz Osteoartridi}

Konu üzerine yapılan çalışmalar, genellikle obezite varlığı ile diz osteoartrid (OA) prevalansı ve insidansı arasında ilişki olduğunu göstermiştir. Obezitenin OA'da ana değiştirilebilir risk faktörü olduğu ileri sürülmüştür. Birkaç büyük kohort çalışması, OA ve kemik hacminin tanısal değişiklikleri de dahil olmak üzere OA'nın radyografik değerlendirmesini kullanarak bu bulguları desteklemiştir. ${ }^{10}$ Ağırlık kazanım süreci de bu durumla ilişkili olabilir. Yetişkin yaşamında normal kilodan fazla kiloya geçiş, sürekli kilolu olmaktan ziyade, artroplasti gerektiren diz OA için daha yüksek risk taşımaktadır. ${ }^{11}$

Obezite ve OA arasında sadece radyografik değişikliklerden ziyade hasta semptomlarını kullanarak benzer bir ilişki göstermeyi amaçlayan bazı çalışmalar, BKİ'nin radyografik özelliklerden bağımsız olarak diz ağrısının bir öngörücüsü olduğunu bulmuştur. $^{12}$

Mekanik, humeral, metabolik ve genetik faktörlerin değişken bir kombinasyonunun OA patogenezinde rol oynadığ düşünülmektedir. Obezite ile fazla kilo eklem yükünü arttırır, bu da ağırlık taşıyan eklemler üzerinde zararlı etkiler yaratır. Ek kütle, artiküler kıkırdağı biyolojik özelliklerin ötesinde strese sokabilir ve bu nedenle dejeneratif değişikliklere neden olabilir. Yürüyüş analizi, diz eklemi boyunca yükü azaltmak için kilo kaybının yararlı olduğunu göstermiştir, yaklaşık $0.5 \mathrm{~kg}$ ağırlık kaybı, adım başına iki ila dört kat yükte azalmaya neden olmaktadır. ${ }^{10}$

OA, kıkırdak üretilenden daha hızlı parçalandığında gelişir. İskelet kası kütlesindense vücut yağ kütlesi, kıkırdak defektleri için bir risk faktörüdür; toplam vücut yağındaki her $1 \mathrm{~kg}$ artış için, erken diz OA'nın bir özelliği olan artmış kıkırdak kusurları riski vardır. Eller gibi ağırlık taşımayan eklemlerde OA bulunmazken, daha yüksek BKİ ve vücut yağı olan 
bireylerde daha yüksek OA insidansı bulunması metabolik ve humeral faktörlerin etkisini açıklamaktadır. ${ }^{13}$ Benzer şekilde, metabolik sendrom diz OA riskini arttırırken, kalça OA riskini arttırmaz, bu da mekanik faktörlerin tek başına sorumlu olmayabileceğini düşündürmektedir. ${ }^{10}$

\section{Obezite ve Osteoporoz}

Osteoporoz kemik kitlesindeki düşüş ve kemik kitlesinin kırılganlığında yükselme ile tanımlanan bir hastalıktır. Osteoporoz kırık oluşumu sonucunda ölüm ve hastalıklara yol açabilen önemli bir sağlık problemidir. Obezitenin kemik yapımına olumlu etkisi ve çözülümünün azaltılmasıyla toplam kemik metabolizması üzerine olumlu etkiler sağlamaktadır ${ }^{13}$. Yapılan bir çalışmada obez yetişkinler, normal yetişkinlere göre daha yüksek kemik mineral yoğunluğuna, daha kalın ve daha yoğun kortekslere ve daha yüksek trabeküler sayılara sahiptir. Yaşlı gruptaki obez ve normal kişiler arasındaki büyük farklılıklar, obezitenin yaşa bağlı kemik kaybına karşı koruyabileceğini ve ayrıca pik kemik kütlesini artırabileceğini göstermektedir. Kemik döngüsü belirteçleri (BTM'ler) serum kolajen tip $1 \mathrm{C}$-telopeptit (CTX) ve tip 1 prokolajen $\mathrm{N}$-terminal peptit (PINP) ölçüldüğünde görülmüştür ki obez yetişkinler, daha düşük CTX ve PINP değerleri ile normal BKİ'ye sahip bireylere kıyasla daha düşük kemik döngüsüne sahiptir. Obez yetişkinlerde kemik oluşumu ile kemik çözünümü arasında pozitif bir denge olduğu gösterilmiştir. $\mathrm{Bu}$ bulgular mevcut literatürle de uyumludur. ${ }^{14}$ Ayrıca, yetişkinlikte ve ileri yaşta toplam kemik kütlesi üzerine olumlu etkiler sağlamaktadır. Menapoz sonrası dönemde kemik kütlesi kaybını yavaşlatarak olumlu katkı sağlar. Sekonder osteoporoz sebepleri olan endojen veya ekzojen Cushing sendromu gibi durumlarla birlikte de obezite görülebilmektedir. Obezitenin, yapılan çalışmalarda bazı bölgelerde, kırık riskini artırırken bazı bölgelerde ise koruyucu etkileri bulunduğu saptanmıştır. Düşük BKI'nin artan kalça kemiği kırığı riski ile ilişkisi gösterilmiştir. Obezite varlığında ayrıca, postmenopozal kırıklar artmış prevelans gösterir. Proksimal femur ve vertebral kırıklar BKİ'nin 30'un üzerinde olduğu hastalarda daha az oranda görülmektedir. Ancak proksimal humerus, üst bacak ve ayak bileği kırık riski BKI'nin 30 üzerinde olduğu hastalarda artış gösterir. ${ }^{15}$

\section{Obezite ve Enflamatuar Romatizmal Hastalıklar}

Son dönemlerde yapılan çalışmalarda, fazla kilolu olmak veya BKI'nin 30'un üzerinde olması; metabolik hastalıklar, neoplastik sorunlar yaşamak ve kardiyovasküler hastalıkların riskinde artışa sebep olmanın yanında, enflamasyon aktivitesinin arttığ durumlara da sebep olarak gösterilmeye başlanmıştır. Adipositokin veya adipokin olarak adlandırılan mediatörler BKİ'nin 30'un üzerinde olması durumunda veya fazla kilolu hastalarda aktif olan hipertrofik adipositlerden üretilerek serbest bırakılmaktadır. Enflamasyona yol açmalarıyla bilinen ve önemli olan adipokinler; leptin, visfatin, IL-1 ve TNF- $\alpha$ 'dır. Beyaz yağ dokusu hücreleri yalnızca metabolizma için değil aynı zamanda çok sayıda enflamasyona yol açan sitokin ve adipokinlerin sayesinde enflamasyona ve bağ ${ }_{1 S ̧ 1} 1 \mathrm{l} l \mathrm{k}$ sürecine etki eden aktif bir endokrin organ gibi etkinlik göstermektedir. ${ }^{15}$ Yüksek miktarda yağ dokusu, bir enflamasyon kaynağıdır ve artmış hastalık aktivitesine yol açar. Romatoid Artrit (RA); RA hastaları arasında obezite prevelansı \%18-31 arasındadır ve genel popülasyondan daha yüksek bulunmuştur. Ayrıca genel olarak bakıldığında, RA hastalarının \%60'ının BKI değerinin 25 üzerinde olduğu bulunmuştur, bu oran genel populasyona oranla daha yüksektir. Yapılan bir çalışmada 55 yaşından daha küçük kadınlarda 10 yıl ve daha fazla süre BKİ'nin 30 üzerinde olmasının RA gelişimini $\% 37$ olarak artırdığ 1 tespit edilmiştir. ${ }^{16}$

Vücut yağ kütlesini karakterize eden yöntemlerin kullanılmasıyla yapılan bir çalışmada RA hastalarının, benzer BKI'lerde sağlıklı kontrol grubu ile kıyaslanmasında, daha fazla vücut yağına sahip oldukları tespit edilirken, erkek RA hastalarının daha fazla visseral yağ dokuya ve kadın RA hastalarının daha fazla subkutanöz yağ dokuya sahip oldukları görülmüştür. ${ }^{17}$

Obeziteyle Spondilartritlerin (SpA) ilişkisini araştıran kısıtlı çalışma vardır. Gerçekleştirilen 155 hastadan oluşan bir kohort çalışmada altı ay takip sonrası ankilozan spondilit (AS) hastalarında ilaç tedavisinde obez bireylerde normal kilodaki bireylere göre anlamlı şekilde daha düşük tedaviye yanıtı saptanmıştır. Bir diğer çalışmada ise anti-TNF tedavinin ilk uygulanması sirasında 12 aylık takip sonucunda aksiyel SpA hastalarının tedavi yanıtının BKİ artışıyla negatif korelasyon gösterdiği, obez hastalarda tedaviye daha az yanıt alındığı saptanmıştır. ${ }^{18,19}$

Sistemik Sklerozda (SSk) BKI'nin 30 üzerinde olması prevelansı \%9-18 aralığındadır. Yaygın cilt tutulumlu yaşayan kadın hastalardan edinilen bu veriler sınırlı cilt tutulumuna sahip hastaların durumunu yansıtmamaktadır ve bu orana dahil değildir. Geniş popülasyon tabanlı yapılan bir diğer araştırmada ise 65 yaş üstü erkek ve kadın SSk hastalarında kalp ve damar hastalıkları riskinin yüksek olduğu ve akciğer fonksiyonlarının da etkilendiği, abdominal yağ dokunun bu durumla ilişkisinin olduğu gösterilmiştir. ${ }^{15}$

Gut hastalığının tanımı, eklemlerde monosodyum ürat kristalleri birikmesidir, gut erişkinlerde yaygın olarak görülen oto-enflamatuar bir hastalıktır. Hastalık klasik olarak metabolik sendromla yani obezite, hipertansiyon ve lipit metabolizma bozukluklarının birarada görüldüğü durumla yakından ilişsilendirilmektedir. Gut ile obezitenin 
ilişkilendirilmesi M.Ö. 5. yüzyıla kadar dayanır ve adipoz doku gut hastalığı için kritiktir. Obez olmak, gut hastalığı için bağımsız bir risk faktörü oluşturmaktadır. Visseral yağlanma obezite oluşmadan bile gut hastalığının oluşmasında önemli bir risk faktörüdür. Yağ doku depolanması gut gelişimi ve hiperürisemi ile anlamlı şekilde ilișkili olup serumda ürik asit konsantransyonu adipokinlerden leptin ile benzer, adiponektin ile de ters korelasyon göstermektedir. ${ }^{20}$

\section{SONUC}

Obezite büyüyen adipoz doku hücrelerinin homeostazi sağlamak adına salgıladığı endokrin sinyaller sonucu sistemik enflamatuar bir durum oluştururken, aynı zamanda MetS gibi diğer kronik rahatsızlıklarada taban hazırlar. Obezitenin kardiyovasküler hastalık ve tip 2 diyabet ile ilişkisi artık kabul edilen birer gerçektir ancak buna rağmen, obezite ile alakalı metabolik bozukluklardan kaynaklı kas-iskelet sistemi sorunları yeterince sorgulanmamaktadır. Gerek fazla ve dağılımın yanlış olduğu yük ile ilgili mekanik gerekçeli, gerekse enflamatuar nedenlerden kaynaklı obeziteyle ilişkilendirilen kas-iskelet bozukluklarında ideal ağırlığın sağlanması ve ağırlığın iyileştirilmesine yönelik eylemlerin olumlu etkileri yapılan çalışmalarda bulunmaktadır. Uygun diyet programları ve yaşam tarzında yapılan değişimlerle hem hastalıkların ilerlemesinin önüne geçilebilir hem de tedaviye yanıt artırılarak fiziksel aktivite ve işlev sorunlarındaki olumsuzluklar azaltılabilir.

\section{KAYNAKLAR}

1. Altunkaynak BZ, Özbek E. Obezite: nedenleri ve tedavi seçenekleri. Van Tlp Dergisi. 2006;13(4):138-142.

2. World Health Organization. Obesity: preventing and managing the global epidemic. Report of a WHO Consultation (WHO Technical Report Series 894). Publication date: 2000.

3. Wamsteker EW, Geenen R, Iestra J, Larsen JK, Zelissen PM, van Staveren WA. Obesity-related beliefs predict weight loss after an 8-week lowcalorie diet. Journal of the American Dietetic Association. 2005;105(3):441-444.

4. Çelik A. Bariatrik ve metabolik cerrahi. Türkiye Klinikleri Gastroenterohepatoloji-Özel Konular. 2016;9(2):34-45.

5. Lecube A, Monereo S, Rubio MA, et al. Prevention, diagnosis, and treatment of obesity. 2016 position statement of the Spanish Society for the Study of Obesity. Endocrinologia, diabetes y nutricion. 2017;64(1):15-22.
6. Dansinger ML, Gleason JA, Griffith JL, Selker HP, Schaefer EJ. Comparison of the Atkins, Ornish, Weight Watchers, and Zone diets for weight loss and heart disease risk reduction: a randomized trial. Jama. 2005;293(1):43-53.

7. World Health Organisation. Regional Office for Europe. Body mass index, 2014. https://www.euro.who.int/en/healthtopics/disease-prevention/nutrition/a-healthylifestyle/body-mass-index-bmi

8. Akkaya S, Akkaya N. Obezite ve kas iskelet sistemi. Türkiye Klinikleri Endokrinoloji-Özel Konular. 2013;6(1):60-64.

9. Savvidis C, Tournis S, Dede AD. Obesity and bone metabolism. Hormones. 2018;17(2):205-217.

10. Kulkarni K, Karssiens T, Kumar V, Pandit H. Obesity and osteoarthritis. Maturitas. 2016;89:2228.

11. Manninen P, Riihimaki H, Heliövaara $M$, Suomalainen O. Weight changes and the risk of knee osteoarthritis requiring arthroplasty. Annals of the rheumatic diseases. 2004;63(11):1434-1437.

12. Oliveria SA, Felson DT, Cirillo PA, Reed JI, Walker AM. Body weight, body mass index, and incident symptomatic osteoarthritis of the hand, hip, and knee. Epidemiology. 1999:161-166.

13. Scrivo R, Vasile M, Müller-Ladner U, Neumann E, Valesini G. Rheumatic diseases and obesity: adipocytokines as potential comorbidity biomarkers for cardiovascular diseases. Mediators of inflammation. 2013;2013.

14. Evans AL, Paggiosi MA, Eastell R, Walsh JS. Bone density, microstructure and strength in obese and normal weight men and women in younger and older adulthood. Journal of Bone and Mineral Research. 2015;30(5):920-928.

15. Öz B, Karataş A, Akar ZA, Koca SS. Obezite ve kas-iskelet sistemi. Firat Med J. 2018;23:42-47.

16. Lu B, Hiraki LT, Sparks JA, et al. Being overweight or obese and risk of developing rheumatoid arthritis among women: a prospective cohort study. Annals of the rheumatic diseases. 2014;73(11):1914-1922.

17. Katz PP, Yazdany J, Trupin L, et al. Sex differences in assessment of obesity in rheumatoid arthritis. Arthritis care \& research. 2013;65(1):6270.

18. Ottaviani S, Allanore Y, Tubach F, et al. Body mass index influences the response to infliximab in ankylosing spondylitis. Arthritis research \& therapy. 2012;14(3):R115.

19. Gremese E, Bernardi S, Bonazza S, et al. Body weight, gender and response to TNF- $\alpha$ blockers in axial spondyloarthritis. Rheumatology. 2014;53(5):875-881.

20. Zhen H, Gui F. The role of hyperuricemia on vascular endothelium dysfunction. Biomedical Reports. 2017;7(4):325-330. 